\title{
Natural gas fueled compression ignition engine performance and emissions maps with diesel and RME pilot fuels
}

\author{
S. Imran ${ }^{\mathrm{a}, \mathrm{d}}$, D.R. Emberson ${ }^{\mathrm{a}}$, A. Diez ${ }^{\mathrm{b}}$, D.S. Wen ${ }^{\mathrm{e}}$, R.J. Crookes ${ }^{\mathrm{a}}$, T. Korakianitis ${ }^{\mathrm{c}, *}$ \\ ${ }^{a}$ School of Engineering and Materials Science, Queen Mary University of London, Mile End Road, London E1 4NS, UK \\ ${ }^{\mathrm{b}}$ Mechanical Engineering Department, IYTE Izmir Institute of Technology, Urla, Izmir 35430, Turkey \\ ${ }^{\text {c }}$ Parks College of Engineering, Aviation and Technology, Saint Louis University, St. Louis, MO 63103, USA \\ ${ }^{\mathrm{d}}$ Department of Mechanical Engineering, University of Engineering and Technology, Lahore (City Campus), Lahore, Pakistan \\ ${ }^{\text {e }}$ School of Process Environmental and Materials Engineering, University of Leeds, Leeds, LS2 9JU, UK
}

\section{H I G H L I G H T S}

- Compression ignition engine fueled with manifold injected natural gas.

- Engine operated under dual fueling mode with diesel and RME examined as pilot fuels.

- Emissions maps presented for specific emissions of $\mathrm{CO}_{2}, \mathrm{HC}$ and $\mathrm{NO}_{x}$.

- Novel method of presentation for the comparison of data collected from dual fueled CI engine.

- Engine efficiency for a dual fueled engine examined across entire range of operation.

\section{A R T I C L E I N F O}

\section{Article history:}

Received 5 February 2013

Received in revised form 16 February 2014

Accepted 17 February 2014

Available online 4 April 2014

\section{Keywords:}

Contours

Performance maps

Natural gas

Diesel

RME

Combustion

\begin{abstract}
A B S T R A C T
When natural gas is port/manifold injected into a compression ignition engine, the mixture of air and the natural gas is compressed during the compression stroke of the engine. Due to the difference in the values of specific heat capacity ratio between air and natural gas, the temperature and pressure at the time of pilot fuel injection are different when compared to a case where only air is compressed. Also, the presence of natural gas affects the peak in-cylinder (adiabatic flame) temperature. This significantly affects the performance as well as emissions characteristics of natural gas based dual fueling in CI engine. Natural gas has been extensively tested in a single cylinder compression ignition engine to obtain performance and emissions maps.Two pilot fuels, diesel and RME, have been used to pilot natural gas combustion. The performance of the two liquid fuels used as pilots has also been assessed and compared. Tests were conducted at 48 different operating conditions (six different speeds and eight different power output conditions for each speed) for single fueling cases. Both the diesel and RME based single fueling cases were used as baselines to compare the natural gas based dual fueling where data was collected at 36 operating conditions (six different speeds and six different power output conditions for each speed). Performance and emissions characteristics were mapped on speed vs brake power plots. The thermal efficiency values of the natural gas dual fueling were lower when compared to the respective pilot fuel based single fueling apart from the highest powers. The effect of engine speed on volumetric efficiency in case of the natural gas based dual fueling was significantly different from what was observed with the single fueling. Contours of specific $\mathrm{NO}_{X}$ for diesel and RME based single fueling differ significantly when these fuels were used to pilot natural gas combustion. For both of the single fueling cases, maximum specific $\mathrm{NO}_{X}$ were centered at the intersection of medium speeds and medium powers and they decrease in all directions from this region of maximum values. On the other hand, an opposite trend was observed with dual fueling cases where minimum specific $\mathrm{NO}_{X}$ were observed at the center of the map and they increase in all direction from this region of minimum $\mathrm{NO}_{x}$. $\mathrm{RME}$ piloted specific $\mathrm{NO}_{x}$ at the highest speeds were the only exception to this trend. Higher specific $\mathrm{HC}$ and lower specific $\mathrm{CO}_{2}$ emissions were observed in case of natural gas based dual fueling. The emissions were measured in $\mathrm{g} / \mathrm{MJ}$ of engine power.
\end{abstract}

() 2014 Published by Elsevier Ltd.

\footnotetext{
* Corresponding author. Tel.: +1 2078825301.

E-mail address: korakianitis@alum.mit.edu (T. Korakianitis).
} 


\begin{tabular}{|c|c|c|}
\hline Nomenclature & & \\
\hline $\begin{array}{ll}\text { Greek } & \\
\gamma & \text { specific heat ratio } \\
\text { Abbreviations } \\
\mathrm{CO}_{2} \quad \text { carbon dioxide } \\
\mathrm{NO}_{X} \quad \text { oxides of nitrogen } \\
\mathrm{CO} & \text { carbon mono oxide }\end{array}$ & $\begin{array}{l}\text { CI } \\
\text { DME } \\
\text { IC } \\
\text { CR } \\
\text { RME }\end{array}$ & $\begin{array}{l}\text { HC } \\
\text { hydro carbons } \\
\text { compression ignition } \\
\text { dimethyl ether } \\
\text { internal combustion } \\
\text { compression ratio } \\
\text { rape methyl ester }\end{array}$ \\
\hline
\end{tabular}

\section{Introduction}

Natural gas has long been considered an alternative fuel for the transportation sector and has been used to fuel vehicles since the 1930s. Natural gas is the cleanest fossil fuel available and its proven reserves are 5288.5 trillion cubic feet, much larger than crude oil [1]. Low carbon content and clean burn features (low soot and smoke) have helped the proliferation of natural gas as an alternate fuel with the introduction of ever more stringent emissions standards. Natural gas has properties that are very similar to those of methane $\left(\mathrm{CH}_{4}\right)$, which is its primary constituent. It also contains heavier hydrocarbons such as ethane $\left(\mathrm{C}_{2} \mathrm{H}_{6}\right)$, propane $\left(\mathrm{C}_{3} \mathrm{H}_{8}\right)$, and butane $\left(\mathrm{C}_{4} \mathrm{H}_{10}\right)$, and inert diluents such as molecular nitrogen $\left(\mathrm{N}_{2}\right)$ and carbon dioxide $\left(\mathrm{CO}_{2}\right)$ [3-6].

Natural gas has a low cetane number (compared to diesel fuel) $[2,5,6]$, but it has a high specific heat capacity ratio $\gamma$ (when compared with air). The poor ignition characteristics (extended ignition delay) of low cetane number fuels in $\mathrm{CI}$ engines often prevents ignition entirely at the temperatures found under compression in a $\mathrm{CI}$ engine.

Various ignition strategies are used to ignite natural gas in unmodified $\mathrm{CI}$ engines. A high cetane liquid fuel such as diesel [6-8] or RME [6] have been widely used as an initial source of ignition using the dual fuel concept [9]. The natural gas is most often inducted into the engine in the air intake manifold with the high cetane fuel directly injected into the cylinder. To ensure ignition and sustain acceptable combustion there is a lower limit of the quantity of the high cetane fuel that must be injected [9].

The adiabatic flame temperature of methane in air for phi $=1$ and phi $=0.5$ have been presented by Karim [14]. Assuming an initial temperature of around $800 \mathrm{~K}$ at TDC, the difference in peak temperature (adiabatic flame temperature) between the methane mixture of phi $=1$ and $\mathrm{phi}=0.5$ is in excess of $600 \mathrm{~K}$. The effect of difference in the specific heat capacity ratios of air and natural gas, on the in-cylinder temperature at the end of compression, can be evaluated by using a freely available program REFPROP [15]. When a sample calculation is made at a pressure of $2.5 \mathrm{MPa}$ and a temperature of $500 \mathrm{~K}$, it yields $\gamma=1.3559$ for air and $\gamma=1.3985$ for a stoichiometric mixture of methane and air. With inlet temperature $\left(T_{1}\right)$ set at $300 \mathrm{~K}$, the peak compression temperature $\left(T_{2}\right)$ can be calculated by using the following relationship

$T_{2}=T_{1} \cdot r_{c}^{(\gamma-1)}$

where $r_{c}$ is the compression ratio of the engine used in these tests. The peak compression temperatures calculated in this manner are $837 \mathrm{~K}$ for air and $750 \mathrm{~K}$ for the stoichiometric methane/air mixture. As analyzed above, the presence of natural gas reduces the peak temperature by $100 \mathrm{~K}$ and the adiabatic flame temperature by $500 \mathrm{~K}$

The higher specific heat capacity ratio of natural gas lowers incylinder charge temperature and increases ignition delay compared to the baseline diesel operation and hence is critical from an emissions perspective $[10,11]$. Due to these competing factors dual fueling with natural gas needs to be investigated across a wider range of engine operating conditions to assess the affect of engine speed and load (power output) in addition to the above mentioned factors.

Dual fueling of $\mathrm{CI}$ engine with natural gas has demonstrated a slight reduction of brake thermal efficiency when compared to fueling with standard mineral diesel $[7,8,12-14]$ whereas higher thermal efficiency values were reported at higher loads [16]. Concerning total brake specific fuel consumption, it is revealed that it becomes inferior under dual fuel operation compared to normal diesel operation at the same engine operating conditions because of the smaller heating value of natural gas. At high load, the values of total brake specific fuel consumption under dual fuel operation tend to converge with that of normal diesel operation [7].

$\mathrm{NO}_{X}$ is strongly dependent on local temperatures so most $\mathrm{NO}_{X}$ is expected to form in the region around the pilot spray where high temperatures exist and the equivalence ratio is close to stoichiometric [17]. Earlier and faster combustion events increase the duration for which in-cylinder conditions are suitable for $\mathrm{NO}_{X}$ formation [18]. The use of natural gas under dual fueling in $\mathrm{CI}$ engines significantly affect $\mathrm{NO}_{X}$ emissions: the $\mathrm{NO}_{X}$ concentration under dual fuel operation is lower when compared to normal diesel operation. At the same time, a significant decrease in soot emissions under dual fuel operation has also been reported [3]. On the other hand, $\mathrm{CO}$ and $\mathrm{HC}$ emissions levels have been reported to be considerably higher when compared to normal diesel operation $[7,10-12,19]$.

Whereas literature has been reported on natural gas combustion and emissions under dual fueling conditions in $\mathrm{Cl}$ engines, most of the studies lack one or the other important aspects. The studies are either restricted to various loads/powers at one engine speed (neglecting the effect of engine speed) or one or two load/ power conditions at various speeds (neglecting load variations). There is a scarcity of engine "fuel maps" in the open literature (these are the full contours of thermal efficiency or brake specific fuel consumption plotted throughout the power vs speed range of the engine, or the torque vs speed range of the engine). Sample fuel maps can be found in [20-22]. One such plot of thermal efficiency contours with dual-fueling has been presented previously to demonstrate the thermal efficiency within the operating range of the test engine used in this paper [11]. Maps showing the thermal efficiency as well as specific emissions contours on the powerspeed plots are seldom found in the open literature [23].

The choice of pilot fuel has also been limited to either diesel or biodiesel only and the performance of these two pilots has hardly been investigated and compared over a wider range of operating conditions in compression ignition environment. The study presented here is an effort to fill these gaps in the literature available on natural gas based dual fueling in $\mathrm{CI}$ engines.

A specific engine model may be used as a power source for many different applications, each with its own different load characteristics. For instance the same engine can be used to power: two 
different-size cars; a small marine vessel; an electricity generator; and in several other applications. The procedure of selecting the engine (prime mover) while considering the engine's contours of thermal efficiency on the power-speed range of the engine, and concurrently the load line of the powered device, has been briefly described in [6]. Much of the automotive sales literature available will quote the maximum torque at one engine speed, maximum power at another engine speed (though the engine may be rarely operating at these conditions), and the average fuel consumption and total emissions over one or two strictly-specified drive cycles (which may or may not be representative of the intended use of the buyer). In research papers laboratory experiments of engine performance and emissions are usually conducted at constant equivalence ratio, or constant brake mean effective pressure, or occasionally at constant speed. All of these representations are of some use to the average consumer, but they do little to represent or explain the overall thermal efficiency and emissions characteristics of engines throughout their operating range.

In the work presented in this paper both speed and power are considered for diesel and RME piloted natural gas combustion in a direct injection $\mathrm{CI}$ engine. The results are presented as iso-contours of thermal efficiency, volumetric efficiency and brake specific emissions on a power-speed graph throughout the operating range of the engine. The engine is a standard test engine, typical of the majority of such engines used in the developing economies of the world; and though more-modern engines may have higher thermal efficiency and lower emissions, the shape and regions of contours presented in this paper are representative of those shapes for typical $\mathrm{Cl}$ engines and are applicable to all engine performance and emissions contours. This is a novel approach to representing these data, especially for $\mathrm{CI}$ engines. As one example of the utility of the considerations presented in this paper, the specific $\mathrm{NO}_{X}$ emissions contours presented later illustrate that for the baseline single-fuel diesel configuration the region of high specific $\mathrm{NO}_{X}$ emissions is at intermediate engine speed and power, dropping off at high and low values of engine speed and power, helping to explain the $\mathrm{NO}_{X}$ emission trends presented elsewhere in the literature; while the dual-fueling specific $\mathrm{NO}_{X}$ emissions contours show monotonically increasing trends with increasing engine load and increasing engine speed.

\section{Experimental set up}

A four-stroke single-cylinder Gardner 1L2 compression ignition engine was used, the specifications of which are shown in Table 1. Fig. 1 illustrates the schematic layout of the experimental rig showing hydraulic brake, fuel supply lines, various emission analyzers and instrumentation. The engine has been used to test natural gas (current study) and hydrogen in dual fueling mode.

Pilot fuels are injected directly into the cylinder through the standard engine fuel system. Natural gas is supplied from the mains supply passing through a solenoid valve, two ball valves and two diaphragm valves. The gas then flows through a natural gas flow meter $(0-100 \mathrm{l} / \mathrm{min}$ scale) to be inducted into the engine air inlet manifold via a stainless steel tube along with the incoming air under the engine's own suction. The resultant mixture that is inducted into the cylinder is considered to be a homogeneous mixture of natural gas and air. Air flow measurements are made using an inclined manometer measuring the pressure drop across an orifice plate fitted to a large settling tank in the engines intake system.

For normal $\mathrm{CI}$ engine operation, the load placed on the engine started at $0.126 \mathrm{MPa}$ brake mean effective pressure (BMEP) and went up to $0.566 \mathrm{MPa} \mathrm{BMEP}$ in $0.126 \mathrm{MPa}$ increments. $0.566 \mathrm{MPa}$ is the maximum achievable BMEP with this mains supply of
Table 1

Specifications of the Gardner 1L2 diesel engine and Characteristics of RME used.

\begin{tabular}{ll}
\hline No. of cylinders & 1 \\
Bore & $107.95 \mathrm{~mm}$ \\
Stroke & $152.40 \mathrm{~mm}$ \\
Swept volume & $1394 \times 10^{-6} \mathrm{~m}^{3}$ \\
Clearance volume & $115.15 \times 10^{-6} \mathrm{~m}^{3}$ \\
Compression ratio & $13.11: 1$ \\
Max. power & $11 \mathrm{~kW} @ 1500 \mathrm{rev} / \mathrm{min}$ \\
No. of nozzle holes & 4 \\
Diameter of the nozzle hole & $200 \times 10^{-6} \mathrm{~m}$ \\
IVO & $10^{\circ} \mathrm{BTDC}$ \\
IVC & $40^{\circ} \mathrm{ABDC}$ \\
EVO & $50^{\circ} \mathrm{BBDC}$ \\
EVC & $15^{\circ} \mathrm{ATDC}$ \\
Heating value of RME & $38 \mathrm{MJ} / \mathrm{kg}$ \\
Density of RME & $880 \mathrm{~kg} / \mathrm{m}^{3}$ \\
Cetane number of RME & 54.4 \\
Chemical formula of RME & $\mathrm{C}_{21} \mathrm{H}_{38} \mathrm{O}_{2}$ \\
\hline
\end{tabular}

natural gas. During natural gas dual-fuel operation the amount of pilot fuel injected is set at a flow rate providing 0.126 MPa BMEP during normal engine operation. The engine power output is then increased further by adjusting the flow rate of natural gas inducted by the engine to reach the high power regions.

A Signal 4000VM chemiluminescence analyzer is used to measure wet $\mathrm{NO}_{X}$ emission volume concentrations, while wet unburnt hydrocarbon (HC) emission volume concentrations are measured by a Rotork Analysis model 523 flame ionization detector (FID) analyzer (both analyzers sampled exhaust gas via a heated line at $160{ }^{\circ} \mathrm{C}$ ). A Servomex $4210 \mathrm{C}$ exhaust gas analyzer measured dry volume concentrations of carbon monoxide (CO), carbon dioxide $\left(\mathrm{CO}_{2}\right)$ and oxygen $\left(\mathrm{O}_{2}\right)$ concentrations using non-dispersive infrared sensors and a paramagnetic sensor respectively.

The results were calculated as described in previous publications $[11,24]$. Contours of thermal efficiency and emissions were plotted on brake power vs engine rotational speed (rev/min) figures.

\section{Pressure and rate of energy release data on selected operating conditions}

This section presents pressure and rate of energy release data to support the claims made in the following section. Fig. 2(a and b) presents the in-cylinder pressure and the rate of energy release for diesel and RME fueling at a BMEP of $0.125 \mathrm{MPa}$ while operating at $1000 \mathrm{rev} / \mathrm{min}$. Fig. 3(a and b) presents the in-cylinder pressure and the rate of energy release for diesel and RME fueling at a BMEP of $0.503 \mathrm{MPa}$ while operating at $1000 \mathrm{rev} / \mathrm{min}$.

While operating at lower load, higher peak in-cylinder pressure has been observed [for diesel fuel] when compared to RME. Shorter ignition in case of RME has caused the peak pressure to occur slightly earlier. When the rate of energy release curves for the two fuels were compared, diesel has shown clearly higher rate of energy release peaks. Both peaks for the rate of energy release [for RME fuel] are lower and occur earlier when compared to the ones obtained with diesel. At higher loads, the two fuels have shown similar peak pressures with diesel producing slightly higher peak pressure but the difference in peak pressures for the two fuels is reduced when compared to the lower load case. Similar to the lower load case, the first rate of energy release peak diesel is significantly higher but the second peak for RME is higher when compared to the second peak obtained with diesel at the higher load.

Fig. 4(a and b) in-cylinder pressure and rate of energy release for pure diesel and diesel piloted natural gas at $0.503 \mathrm{MPa}$ with diesel pilot set at $0.125 \mathrm{MPa}$ for the dual fueling case $1000 \mathrm{rev} /$ 


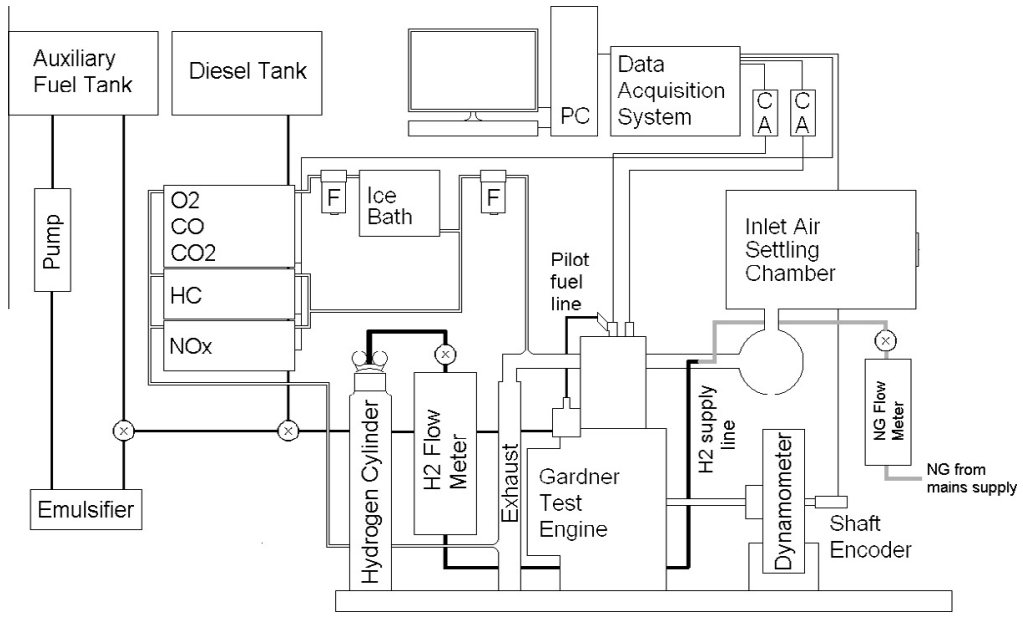

Fig. 1. Experimental rig of dual-fueled $\mathrm{CI}$ engine.

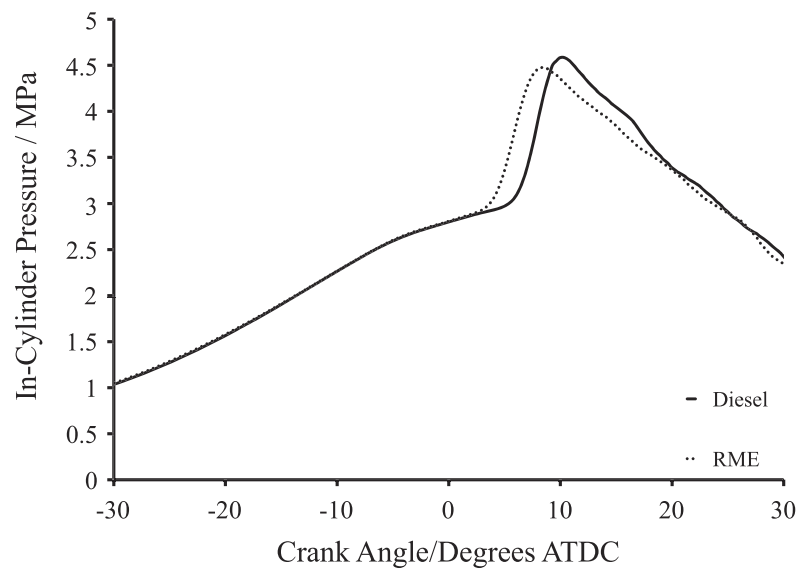

(a)

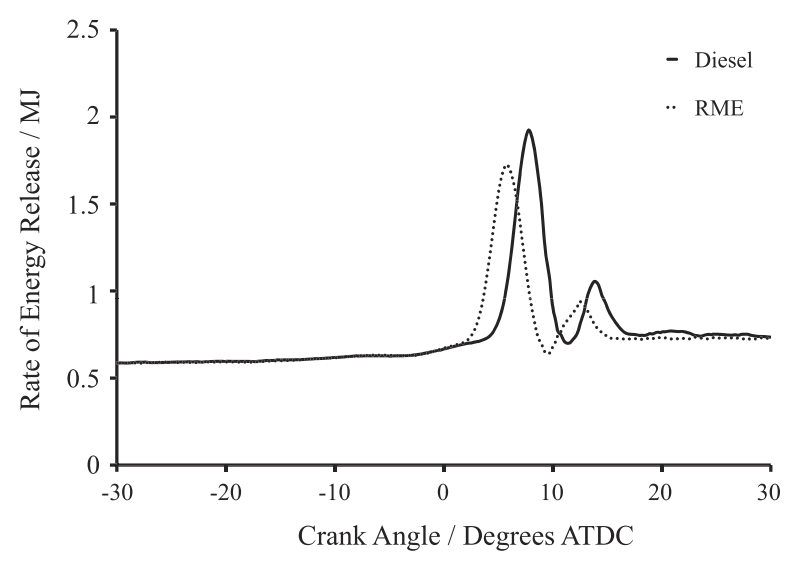

(b)

Fig. 2. Experimentally obtained in-cylinder pressure (a) and rate of energy release (b) for diesel and RME at a BMEP of $0.125 \mathrm{MPa}$ and 1000 rev/min.

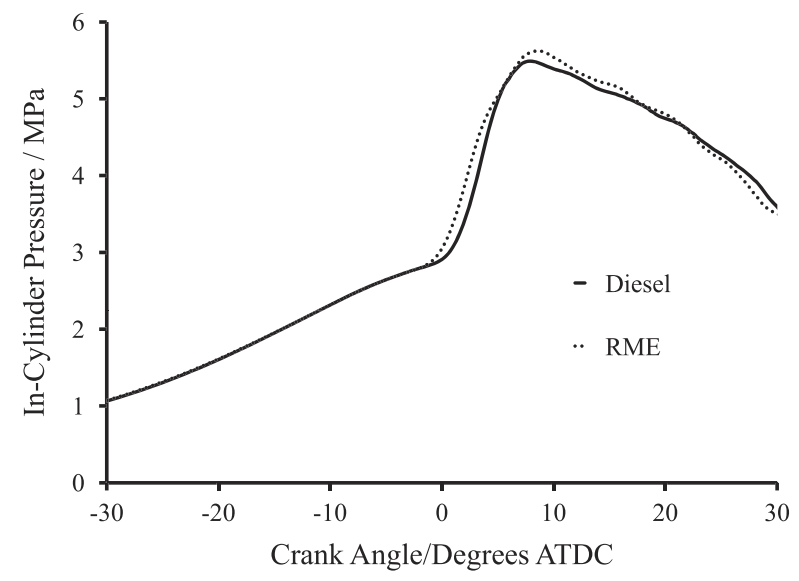

(a)

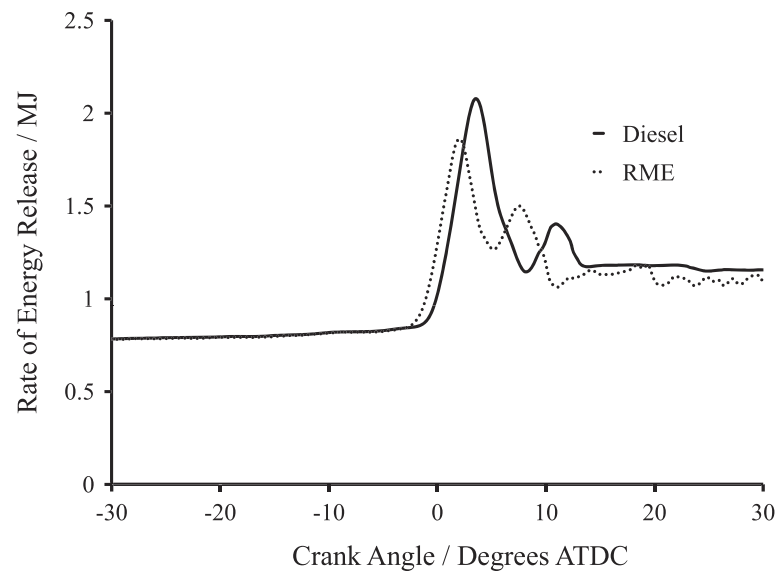

(b)

Fig. 3. Experimentally obtained in-cylinder pressure (a) and rate of energy release (b) for diesel and RME at a BMEP of $0.503 \mathrm{MPa}$ and 1000 rev/min. 


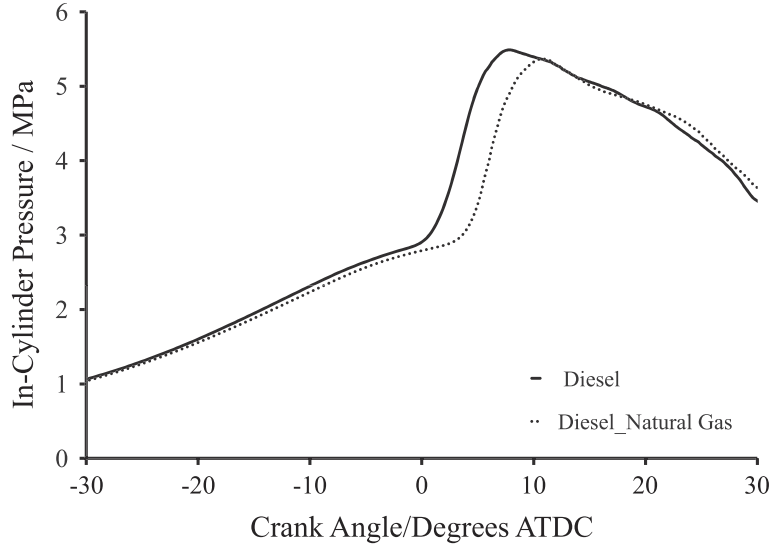

(a)

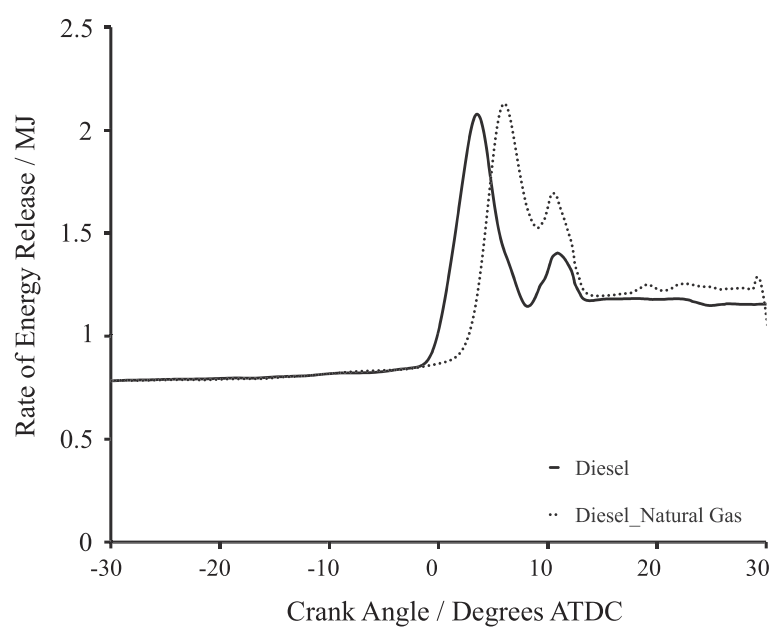

(b)

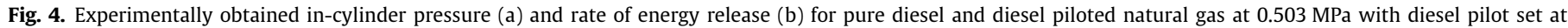
$0.125 \mathrm{MPa}$ for the dual fueling case $1000 \mathrm{rev} / \mathrm{min}$.

min. At a relatively lower load (0.38 MPa), diesel piloted natural gas has produced lower peak pressure when compared to the pure diesel based single fueling whereas similar peak pressures are observed when the two cases are compared at a higher BMEP $(0.503 \mathrm{MPa})$. The rate of energy release peaks for the dual fueling case are comparable to the ones obtained with diesel based single fueling but these occur slightly later in the cycle. Fig. 5(a and b) presents the in-cylinder pressure and the rate of energy release for pure RME and RME piloted natural gas at $0.503 \mathrm{MPa}$ with RME pilot set at $0.125 \mathrm{MPa}$ for the dual fueling case $1000 \mathrm{rev} /$ min. RME based dual fueling of natural gas has exhibited similar peak pressure but clearly higher first rate of energy release peak when compared to the RME based single fueling.

\section{Results and discussion}

This section has been divided into two parts. The first half presents and discusses the experimentally obtained maps of different performance and emissions parameters for diesel piloted dual fueling of natural gas and compares these maps with those obtained in diesel based single fueling mode. The second half presents and discusses the experimentally obtained maps of different perfor-

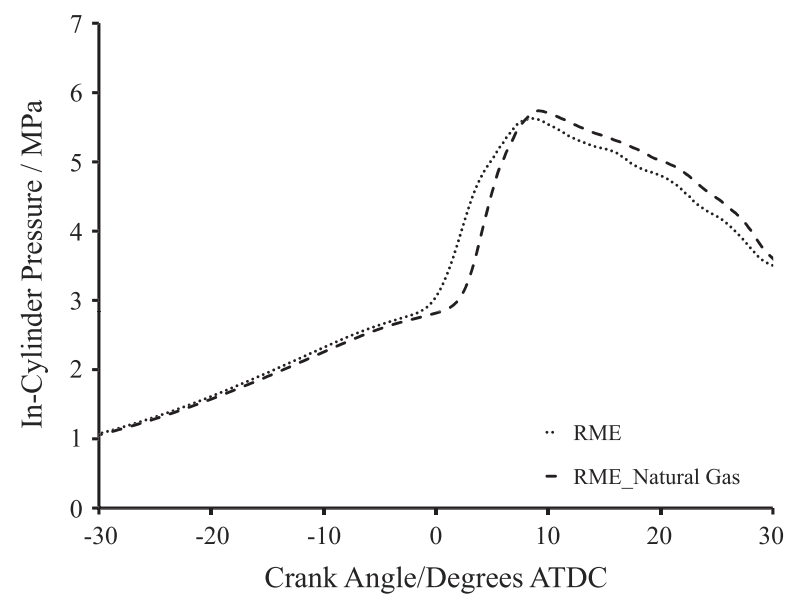

(a) mance and emissions parameters for RME piloted dual fueling of natural gas and compares these maps with those obtained in RME based single fueling mode.

\subsection{Diesel plus NG}

Maps for thermal efficiency, volumetric efficiency, specific $\mathrm{NO}_{X}$, specific $\mathrm{HC}$ and specific $\mathrm{CO}_{2}$ have been presented for diesel based single fueling and diesel piloted dual fueling of natural gas.

\subsubsection{Thermal and volumetric efficiency}

Fig. 6(a) presents an experimentally obtained map showing isocontours of thermal efficiency for diesel based single fueling whereas Fig. 6(b) presents a similar map for diesel piloted dual fueling of natural gas. While operating in dual fuel mode using diesel-ignited natural gas no significant difference (overall) is observed in thermal efficiency when compared to pure diesel operation. At higher power outputs, dual fuel mode produces similar or higher thermal efficiencies as compared to normal fueling mode whereas at relatively lower power outputs, lower values of thermal efficiency have been observed (Fig. 6(b)).

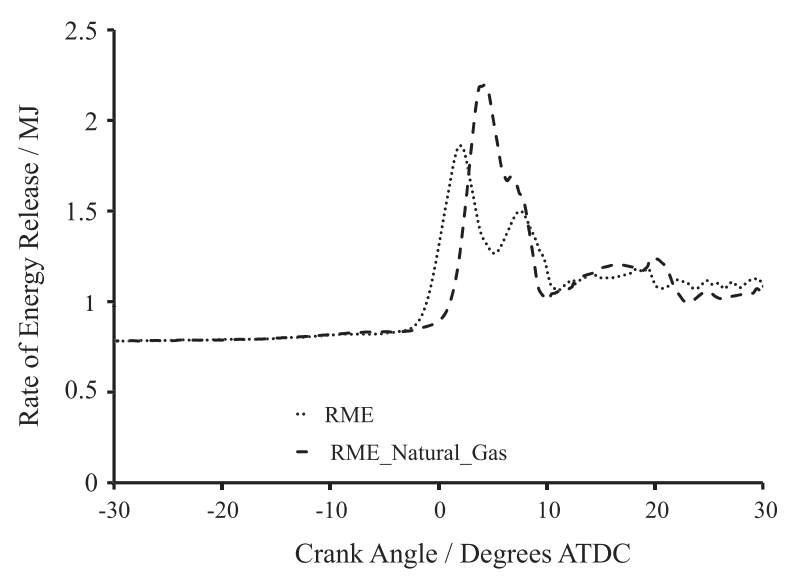

(b)

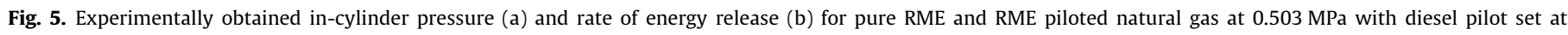
$0.125 \mathrm{MPa}$ for the dual fueling case $1000 \mathrm{rev} / \mathrm{min}$. 


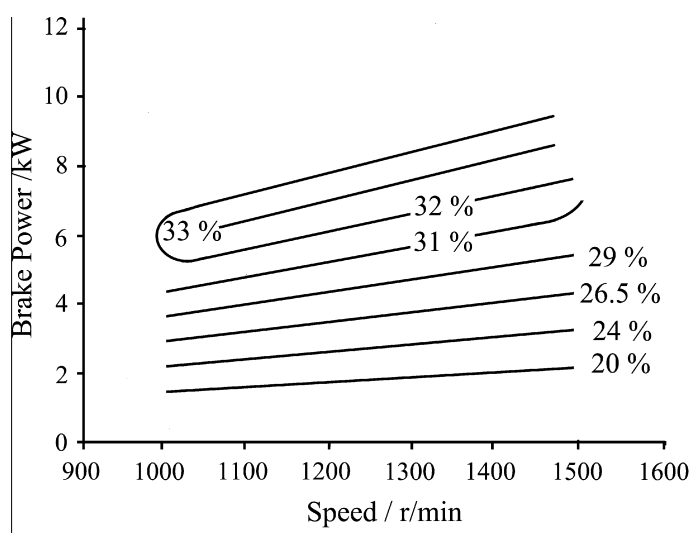

(a) Thermal Efficiency - Diesel

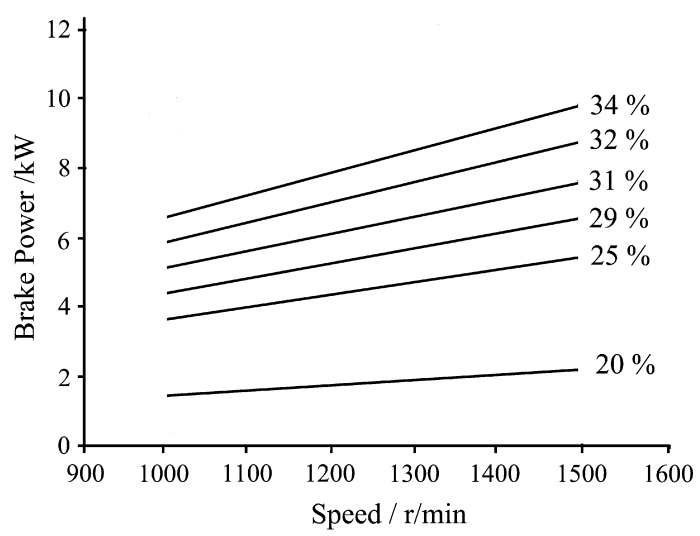

(b) Thermal Efficiency - Diesel Plus NG

Fig. 6. Experimentally obtained thermal efficiency contours of diesel single fueling (a) and diesel piloted natural gas dual fueling (b).

The lower thermal efficiency values at lower power may be attributed to the failure of pilot fuel to ignite and sustain adequate combustion of the natural gas-air mixture. Whilst the local equivalence ratio in the region of the pilot injection may be near unity (stoichiometric), especially during the initial pre-mixed combustion phase, the overall $F / A$ ratio is $0.25 \%$ lower than single diesel fueling at the lower power output. This suggests that the portion of the combustion chamber not in the pilot region contains a lean homogeneous mixture of natural gas and air. At the highest power outputs the dual fuel mode exhibits a $F / A$ ratio $3.73 \%$ higher than that of single diesel fueling. Under these conditions the pilot fuel is igniting a richer homogenous mixture resulting in a $3.1 \%$ (approximately) increase in thermal efficiency. As the power output increases the dual fuel mode recovers the thermal efficiency losses suffered at the lower power outputs with both modes of operation having similar $F / A$ ratios.

Fig. 7(a) presents an experimentally obtained map showing volumetric efficiency trends on a speed-power graph for diesel based single fueling whereas Fig. 7(b) presents a similar map for diesel piloted dual fueling of natural gas. The volumetric efficiency map (Fig. 7(b)) reflects the lower values for dual fuel mode. This is to be expected as a portion of the inducted air is being displaced by the natural gas in the intake, reducing the air partial pressure below that of the mixture pressure. Also as to be expected is the drop of volumetric efficiency as the engine speed increases for both modes of operation (Fig. 7(a and b)). The frictional losses in the air intake are known to increase as the square of engine speed [22]. The slope of the volumetric efficiency contours is flatter for natural gas dual fueling with diesel than for baseline diesel

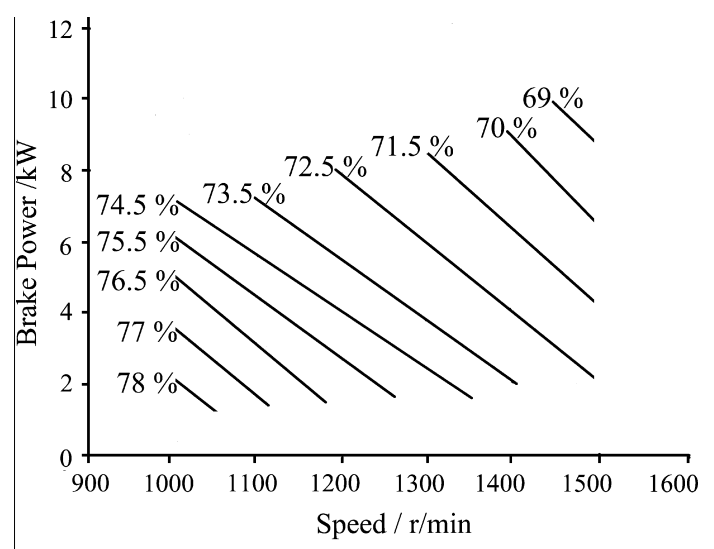

(a) Volumetric Efficiency - Diesel

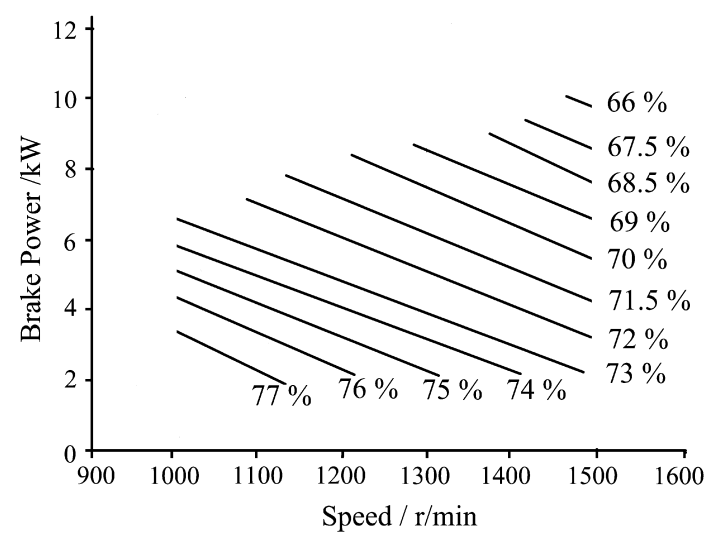

(b) Volumetric Efficiency - Diesel Plus NG

Fig. 7. Experimentally obtained volumetric efficiency contours of diesel single fueling (a) and diesel piloted natural gas dual fueling (b).

operation and the values are lower. This is a consequence of the method used to introduce natural gas into the engine. As the natural gas has been introduced via manifold injection, a portion of the intake air is displaced by the natural gas, reducing the measured volume flow rate of air into the engine. This leads to a reduction of the engine's volumetric flow rate. The slope of the isocontours differs due to a change in the scaling of volumetric efficiency with engine speed. As the amount of natural gas added is increased to meet the increase in speed demand, larger amounts of air are displaced. As the natural gas is introduced at the manifold and does not flow through the entire intake system but the air does, the scaling law as noted by Heywood [22] does not hold.

\subsubsection{Specific $N O_{X}$}

Fig. 8(a) presents an experimentally obtained map showing isocontours of specific $\mathrm{NO}_{X}$ for diesel based single fueling whereas Fig. 8(b) presents a similar map for diesel piloted dual fueling of natural gas. Significant reduction in $\mathrm{NO}_{X}$ is noted with diesel piloted natural gas dual fueling compared to diesel single fueling. The composition of the in-cylinder mixture prior to combustion in case of dual fueling is different from that during diesel single fueling. In case of single fueling the major constituent of the in-cylinder mixture during compression stroke is air along with a fraction of the residual gases from the previous combustion event. Whereas in case of dual fueling, the mixture during compression stroke is composed of a homogeneous mixture of air, natural gas and residual gases. Fig. 9 shows the variation of the specific heat at constant pressure with temperature for air and methane (main 


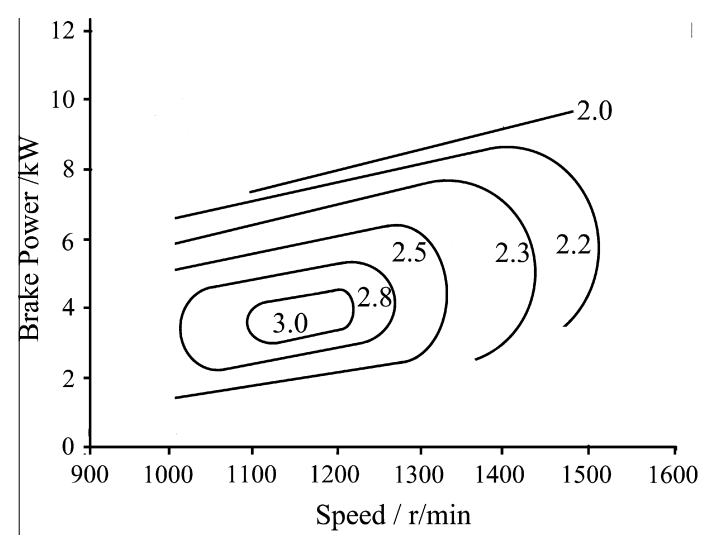

(a) Specific $\mathrm{NO}_{X} / \mathrm{g} / \mathrm{MJ}$ - Diesel

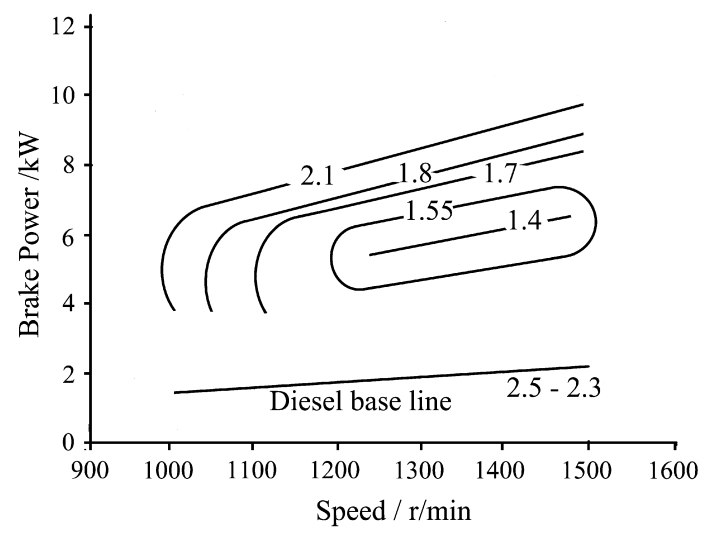

(b) Specific $\mathrm{NO}_{X} / \mathrm{g} / \mathrm{MJ}$ - Diesel Plus NG

Fig. 8. Experimentally obtained specific $\mathrm{NO}_{X}$ contours for diesel single fueling (a) and diesel piloted natural gas dual fueling (b).

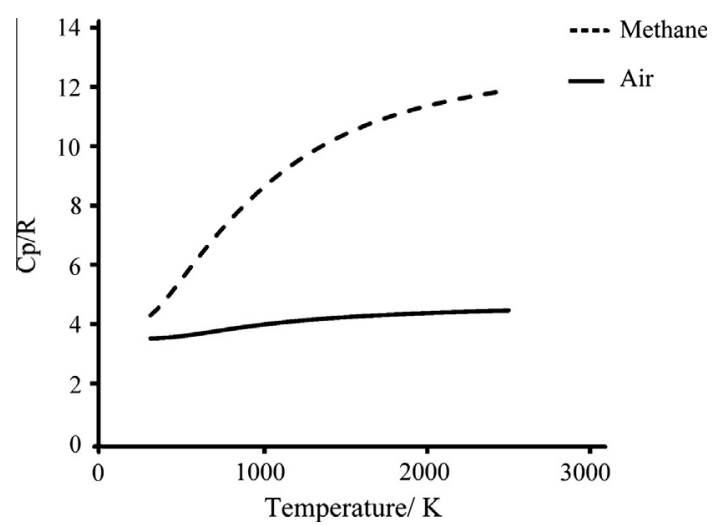

Fig. 9. Specific heat at constant pressure, $C_{P} / \mathrm{R}$ as a function of temperature for air and methane.

constituent of natural gas) and Fig. 10 shows enthalpy contribution of natural gas at different operating conditions.

The specific heat capacity ratio of natural gas is significantly higher than for air. An overall increase in the heat capacity of the in-cylinder mixture as is the case for dual fueling results in a reduced average temperature at the end of the compression stroke. This will lead to an overall lower combustion temperature. With the formation of $\mathrm{NO}_{X}$ highly dependent on the thermal mechanism, the reduced temperature leads to a level of reduced $\mathrm{NO}_{X}$. As the combustion of the homogeneous mixture propagates from a

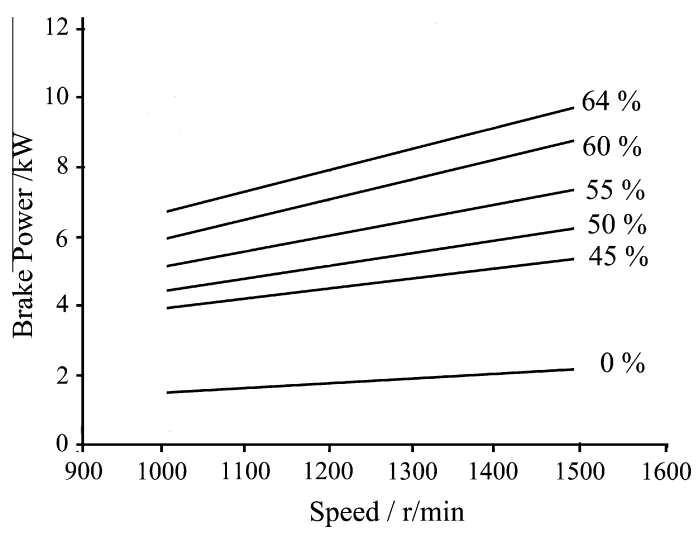

Fig. 10. Enthalpy fraction of natural gas during diesel piloted natural gas dual fueling.

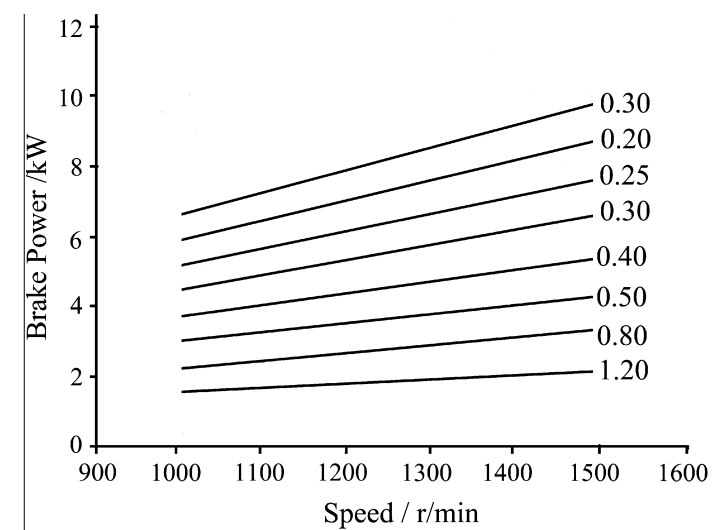

(a) Specific HC /g/MJ- Diesel

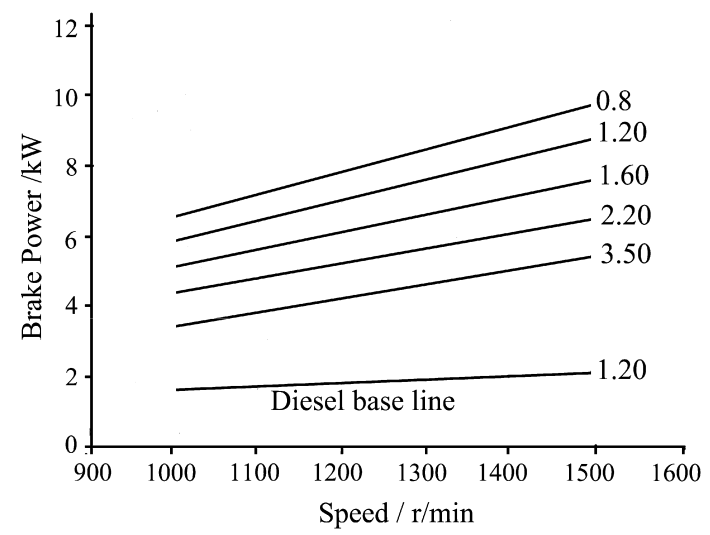

(b) Specific HC/g/MJ - Diesel Plus NG

Fig. 11. Experimentally obtained specific HC contours for diesel single fueling (a) and diesel piloted natural gas dual fueling (b).

number of multi-site ignitions, the increased specific heat capacity will lead to a further reduction of combustion temperature. Reduction in specific $\mathrm{NO}_{X}$ is more significant at lower power where this reduction ranges between $40 \%$ and $53 \%$. At lower powers, the engine is running relatively cooler compared to at higher powers and hence the higher heat capacity has a more pronounced effect on specific $\mathrm{NO}_{X}$.

As is to be expected, as the power output is increased at a constant speed, the absolute $\mathrm{NO}_{X}$ emissions increase due to the increasing in-cylinder temperatures, however Fig. 8(a and b) shows 
specific $\mathrm{NO}_{X}$ emissions across the engine's operational range. For diesel single fueling, as the power output increases the $\mathrm{NO}_{X}$ levels do not increase at the same rate, hence the specific $\mathrm{NO}_{X}$ at the higher powers is actually lower. The peak specific $\mathrm{NO}_{X}$ emissions are centered around low power and low speed conditions. In terms of $\mathrm{NO}_{X}$ emissions, this region is where the engine's combustion temperature and power relationship is at its worst.

\subsubsection{Specific $H C$}

Fig. 11(a) presents an experimentally obtained map showing lines of constant specific $\mathrm{HC}$ for diesel based single fueling whereas Fig. 11(b) presents a similar map for diesel piloted dual fueling of natural gas.

There is a significant increase in the specific $\mathrm{HC}$ emissions at lower and medium power outputs for diesel piloted natural gas dual fueling (Fig. 11(b)) compared to diesel single fueling (Fig. 11(a)). The HC emission iso-contour maps reflects that a significant amount of unburnt natural gas is going into the engine exhaust. One possible explanation for this inefficient burning may be poor flame propagation throughout the homogeneous natural gasair mixture.

The equivalence ratio $(\phi)$ threshold for dual fuel modes is 0.4 . Below this threshold value, the HC emissions increase whereas increasing $\phi$ beyond this value results in a decrease in HC emissions. The equivalence ratio in this case ranges between 0.44 and 0.79 and this is reflected in gradual decrease of $\mathrm{HC}$ emissions as the load increases. When natural gas contributes approximately $45 \%$ of the total enthalpy (Fig. 10) the specific HC emissions increase by about $800 \%$. As the load is increased, the difference

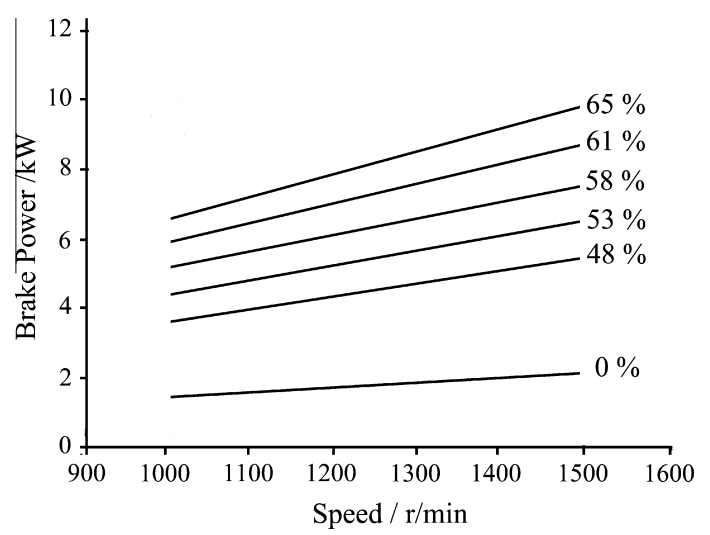

Fig. 13. Enthalpy fraction of natural gas during RME piloted natural gas dual fueling.

between the two modes (single and dual fuel modes) in terms of specific HC emissions is narrowed down. At maximum load conditions when natural gas enthalpy fraction is more than $60 \%$, the dual fuel case produces $250 \%$ more specific HC emissions when compared to the diesel single fueling which reflects a percentage decrease of about $20 \%$ when compared to the case when natural gas contributed about $45 \%$ of the total enthalpy required. These higher HC numbers in dual fueling case can again be attributed to deteriorated combustion (especially in the pre-mixed phase)

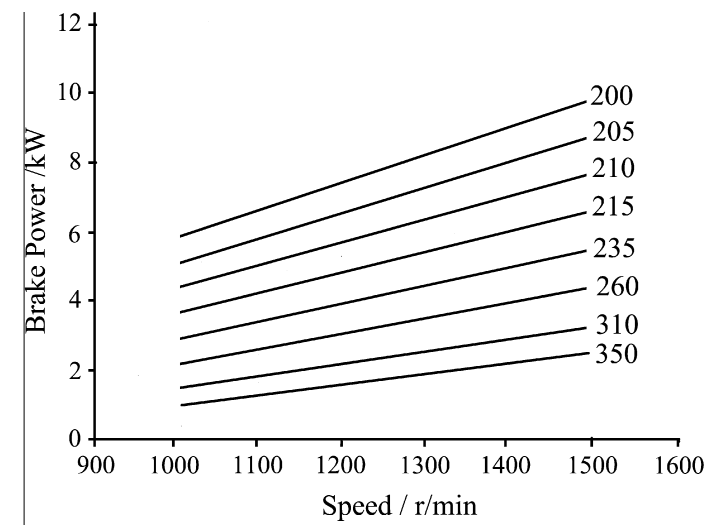

(a) Specific $\mathrm{CO}_{2} / \mathrm{g} / \mathrm{MJ}$ - Diesel

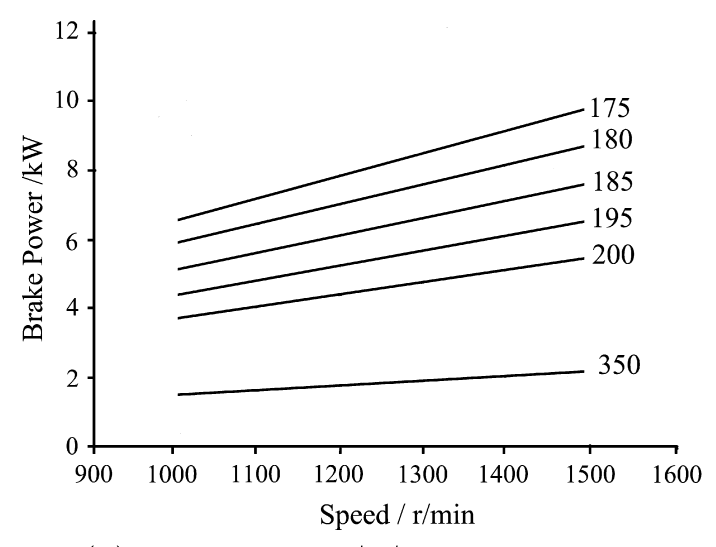

(b) Specific $\mathrm{CO}_{2} / \mathrm{g} / \mathrm{MJ}$ - Diesel Plus NG

Fig. 12. Experimentally obtained specific $\mathrm{CO}_{2}$ contours for diesel single fueling (a) and diesel piloted natural gas dual fueling (b).

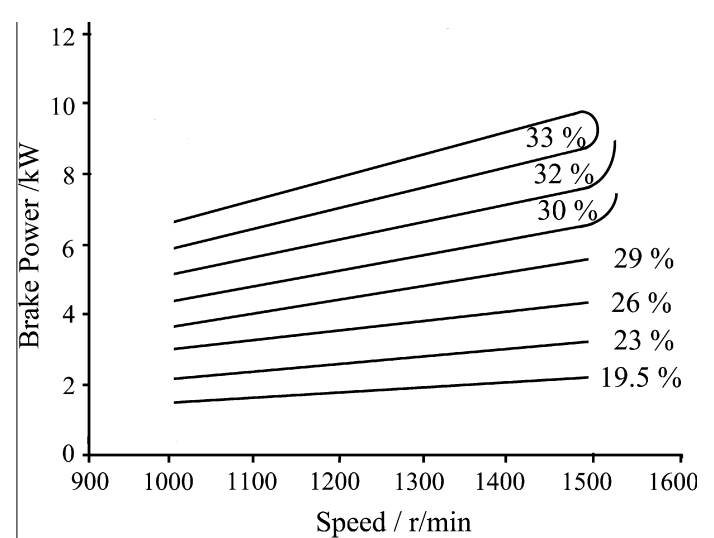

(a) Thermal Efficiency - RME

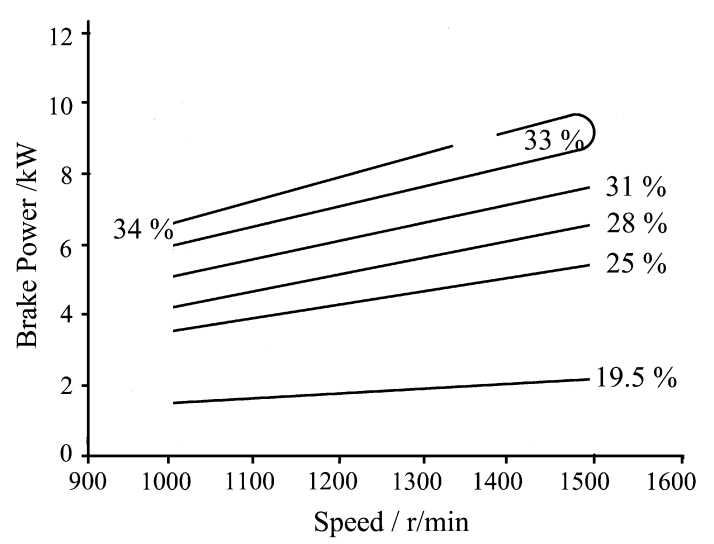

(b) Thermal Efficiency - RME Plus NG

Fig. 14. Experimentally obtained thermal efficiency contours of RME single fueling (a) and RME piloted natural gas dual fueling (b). 


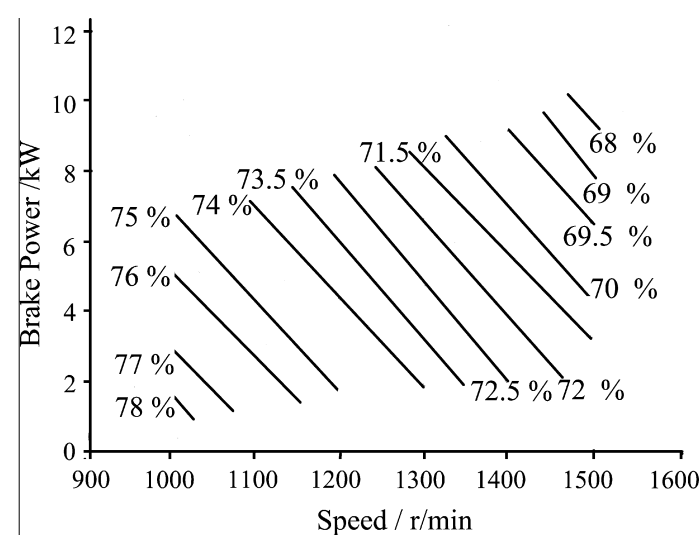

(a) Volumetric Efficiency - RME

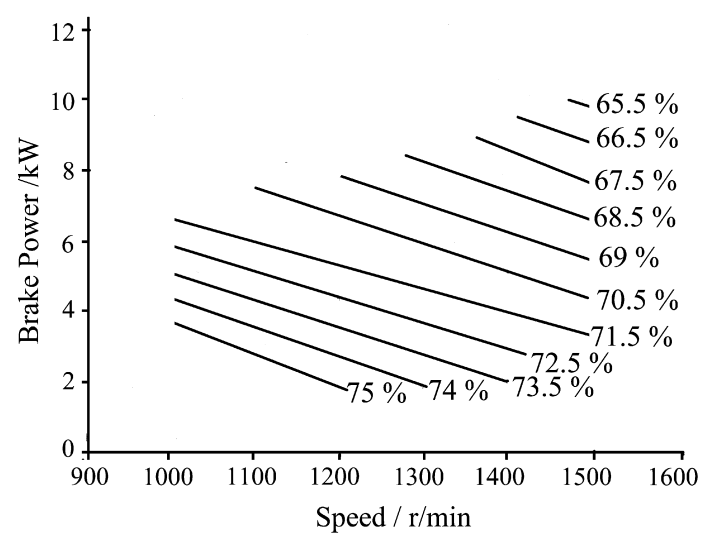

(b) Volumetric Efficiency - RME Plus NG

Fig. 15. Experimentally obtained volumetric efficiency contours of RME single fueling (a) and RME piloted natural gas dual fueling (b).

due to low temperature of the in-cylinder mixture as explained in the $\mathrm{NO}_{X}$ section.

\subsubsection{Specific $\mathrm{CO}_{2}$}

Fig. 12(a) presents an experimentally obtained map showing lines of constant specific $\mathrm{CO}_{2}$ for diesel based single fueling whereas Fig. 12(b) presents a similar map for diesel piloted dual fueling of natural gas. Diesel piloted natural gas dual fueling produces less $\mathrm{CO}_{2}$ emissions. $\mathrm{CO}_{2}$ emissions decreases by $23-30 \%$ when diesel is substituted by diesel plus natural gas dual fuel. This decrease in $\mathrm{CO}_{2}$ can be attributed to lower carbon to hydrogen ratio in case of dual fueling. Stoichiometrically, one gram of methane produces $2.0 \mathrm{~g}$ of $\mathrm{CO}_{2}$ as compared to $3.2 \mathrm{~g}$ produced by $1.0 \mathrm{~g}$ of diesel (37.5\% difference).

\subsection{RME plus NG}

Maps for thermal efficiency, volumetric efficiency, specific $\mathrm{NO}_{X}$, specific $\mathrm{HC}$ and specific $\mathrm{CO}_{2}$ have been presented for RME based single fueling and RME piloted dual fueling of natural gas.

\subsubsection{Thermal and volumetric efficiency}

Enthalpy contribution of natural gas in an RME piloted dual fueling of the natural gas across different operating conditions has been shown in Fig. 13). It ranges between $48 \%$ at relatively lower loads to and $65 \%$ at the highest loads across different speeds (Fig. 14(a) presents an experimentally obtained map showing isocontours of thermal efficiency for RME based single fueling

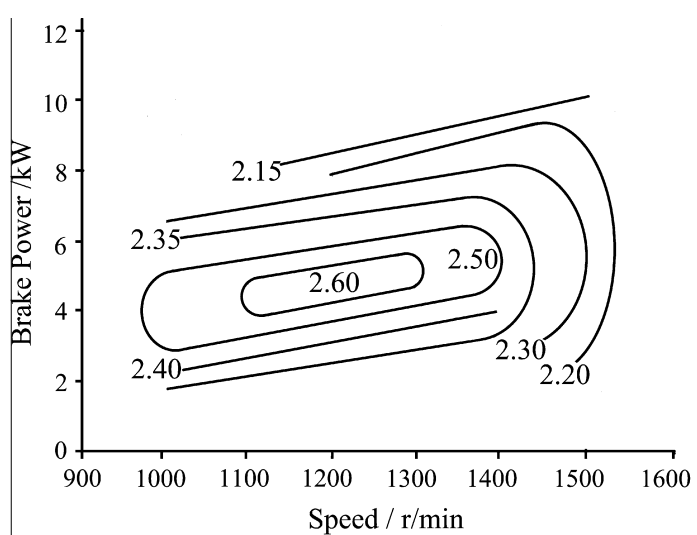

(a) Specific $\mathrm{NO}_{X} / \mathrm{g} / \mathrm{MJ}-\mathrm{RME}$

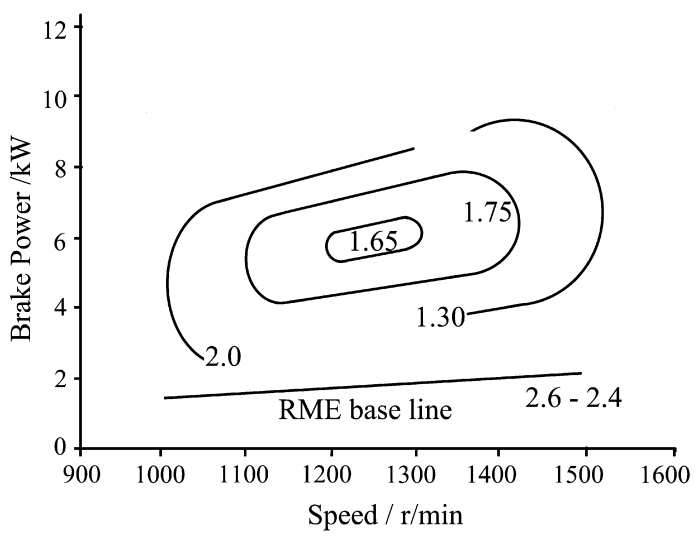

(b) Specific $\mathrm{NO}_{X} / \mathrm{g} / \mathrm{MJ}$ - RME Plus NG

Fig. 16. Experimentally obtained specific $\mathrm{NO}_{X}$ contours for RME single fueling (a) and RME piloted natural gas dual fueling (b).

whereas Fig. 14(b) presents a similar map for RME piloted dual fueling of natural gas. RME piloted dual fueling exhibits slightly inferior thermal efficiency at lower and medium loads when compared to the single fueling case (Fig. 14(b)). When compared to RME based single fueling operation (Fig. 14(a)), the RME piloted dual fueling of natural gas shows a decreases of $13 \%, 5 \%$ and $1.5 \%$ in thermal efficiency when the enthalpy fraction (Fig. 13) of natural gas was $48 \%, 53 \%$ and $58 \%$ respectively.

No significant difference in thermal efficiency is observed when the natural gas enthalpy fraction was $60 \%$ or above. As discussed in Section 4.1.1, this is believed to be an effect of the pilot fuel failing to ignite and sustain acceptable combustion in the overall lean homogeneous mixture of natural gas and air. As with the diesel piloted dual fueling, this argument is supported by the HC emissions for dual fueling (Fig. 11(b)) which decrease significantly with increasing power output.

Fig. 15(a) presents an experimentally obtained map showing lines of constant volumetric efficiency for RME based single fueling whereas Fig. 15(b) presents a similar map for RME piloted dual fueling of natural gas. The volumetric efficiency map (Fig. 15(b)) reflects the lower values for dual fuel mode. As with the case for diesel piloted dual fueling as discussed in Section 4.1.1 this trend is to be expected as a portion of the inducted air is being displaced by the natural gas in the intake. The value and slope of the constant volumetric efficiency lines for RME piloted dual fuel mode (Fig. 15(b)) differ slightly from those for diesel piloted dual fuel mode Fig. 7(b). This can be attributed to the slightly lower heating value of RME compared to diesel. This leads to a larger portion of 


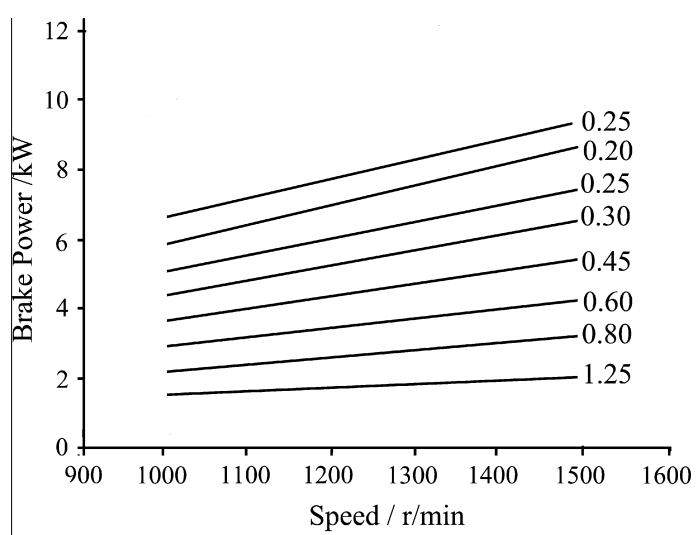

(a) Specific HC /g/MJ - RME

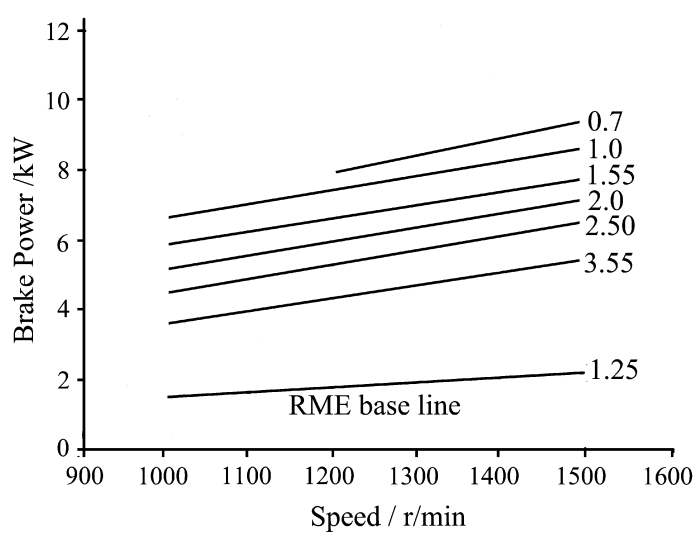

(b) Specific HC /g/MJ- RME Plus NG

Fig. 17. Experimentally obtained specific HC contours for RME single fueling (a) and RME piloted natural gas dual fueling (b).

the total enthalpy in the cylinder coming from the natural gas, meaning a larger portion of the intake air is displaced by the natural gas.

\subsubsection{Specific $N O_{X}$}

Fig. 16(a) presents an experimentally obtained map showing iso-contours of specific $\mathrm{NO}_{X}$ for RME based single fueling whereas Fig. 16(b) presents a similar map for RME piloted dual fueling of natural gas. When compared to RME based single fueling, the RME based dual fueling results in overall lower specific $\mathrm{NO}_{X}$. This observation holds very good for all range of speed and load combinations. Quantitatively, the difference between specific $\mathrm{NO}_{X}$ is the lowest at the junction of higher loads and medium speeds where it is approximately $7 \%$. At medium loads and medium speeds, the specific $\mathrm{NO}_{X}$ in dual fueling mode are reduced by approximately $40 \%$. At higher speeds for all range of load, the specific $\mathrm{NO}_{X}$ reduction ranges between $40 \%$ and $43 \%$. Another interesting observation is the variation in location of the maximum specific $\mathrm{NO}_{X}$. While operating in single fuel mode, the maximum specific $\mathrm{NO}_{X}$ are approximately concentrated at the junction of medium loads and medium speeds. This holds good both for diesel (Fig. 8(a)) as well as RME (Fig. 16(a)). Moving outwards from the position of maximum $\mathrm{NO}_{X}$ results in gradual decrease in specific $\mathrm{NO}_{X}$ numbers. On the other hand, the specific $\mathrm{NO}_{X}$ contours for the two dual fueling cases reflect an opposite trend. Medium load and medium speed combination carries the lowest specific $\mathrm{NO}_{X}$ and a gradual increase in specific $\mathrm{NO}_{X}$ is observed on all outward contours. The only exception to this trend are the specific $\mathrm{NO}_{X}$ contours at higher

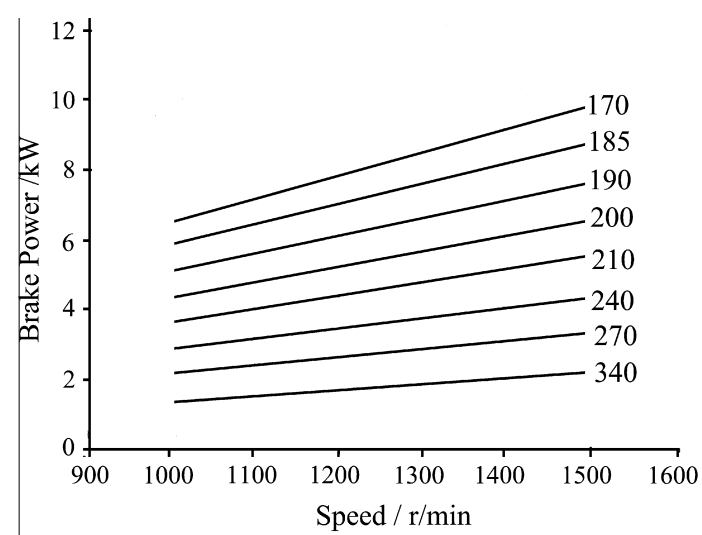

(a) Specific $\mathrm{CO}_{2} / \mathrm{g} / \mathrm{MJ}-\mathrm{RME}$

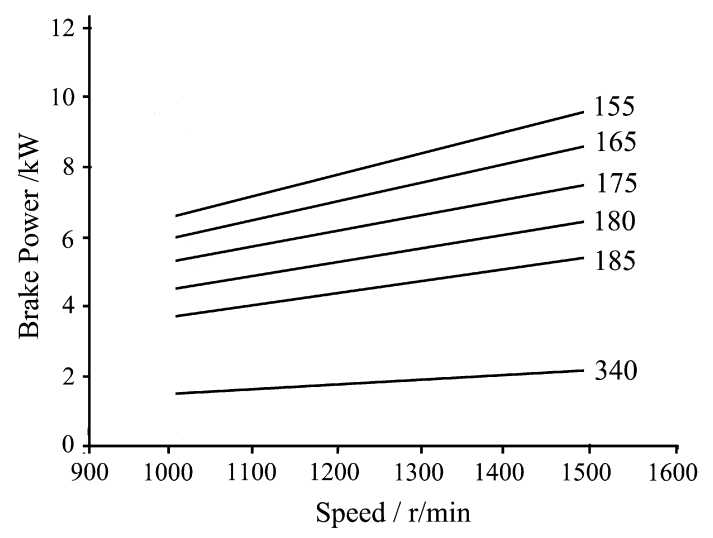

(b) Specific $\mathrm{CO}_{2} / \mathrm{g} / \mathrm{MJ}$ - RME Plus NG

Fig. 18. Experimentally obtained specific $\mathrm{CO}_{2}$ contours for RME single fueling (a) and RME piloted natural gas dual fueling (b).

speeds. The specific $\mathrm{NO}_{X}$ maps both for diesel (Fig. 8)) and RME (Fig. 16(b)) piloted dual fueling case reflect that the latter produces slightly higher specific $\mathrm{NO}_{X}$ as compared to the former. This difference in specific $\mathrm{NO}_{X}$ numbers for the two dual fueling cases can be explained by relatively higher absolute $\mathrm{NO}_{X}$ numbers in case of RME and a slight variation in thermal efficiency (Figs. 6(b) and 14(b)).

\subsubsection{Specific $H C$}

Fig. 17(a) presents an experimentally obtained map showing lines of constant specific HC for RME based single fueling whereas Fig. 17(b) presents a similar map for RME piloted dual fueling of natural gas. When compared to RME based single fueling case, the RME piloted combustion of natural gas results in higher specific HC emissions. So far as the comparison of these two modes involving RME is concerned, the explanation put forward in specific HC section (Section 4.1.3) of diesel piloted combustion of natural gas holds for RME piloted combustion of natural gas as well. When the two dual fueling cases are concerned, there is no significant difference in HC values when RME substitutes diesel as pilot fuel for natural gas combustion in $\mathrm{CI}$ engines. When compared to the diesel piloted dual fueling of natural gas (Fig. 11(a)), a slight reduction in $\mathrm{HC}$ values at higher loads when RME pilots the natural gas combustion can be attributed to higher equivalence ratio at these conditions. This higher equivalence ratio is caused by extra in-fuel oxygen in case of RME. At lower and medium loads, RME led combustion of natural gas has resulted in higher specific HC emissions. This may be attributed to the argument proposed in 
Table 2

Performance comparison of diesel and RME as pilot fuels in natural gas combustion.

\begin{tabular}{|c|c|c|c|c|}
\hline $\begin{array}{l}\text { Pilot } \\
\text { fuel }\end{array}$ & $\begin{array}{l}\text { Natural gas } \\
\text { enthalpy fraction } \\
(\%)\end{array}$ & $\begin{array}{l}\text { Thermal } \\
\text { efficiency \%ge } \\
\text { change }\end{array}$ & $\begin{array}{l}\text { Specific HC } \\
\text { \%ge change }\end{array}$ & $\begin{array}{l}\text { Specific } \mathrm{CO}_{2} \\
\text { \%ge change }\end{array}$ \\
\hline Diesel & $\begin{array}{l}45 \\
50 \\
55 \\
60 \\
64\end{array}$ & $\begin{array}{l}13.79 \% \downarrow \\
6.45 \% \downarrow \\
3.22 \% \downarrow \\
3.03 \% \downarrow \\
6.25 \% \uparrow\end{array}$ & $\begin{array}{l}875 \% \uparrow \\
730 \% \uparrow \\
635 \% \uparrow \\
600 \% \uparrow \\
266 \% \uparrow\end{array}$ & $\begin{array}{l}17.5 \% \downarrow \\
9.3 \% \downarrow \\
11.9 \% \downarrow \\
12.2 \% \downarrow \\
12.5 \% \downarrow\end{array}$ \\
\hline RME & $\begin{array}{l}48 \\
53 \\
58 \\
61 \\
65\end{array}$ & $\begin{array}{l}13.79 \% \downarrow \\
6.66 \% \downarrow \\
3.22 \% \downarrow \\
0 \% \downarrow \\
0-3.03 \% \uparrow\end{array}$ & $\begin{array}{l}788 \% \uparrow \\
830 \% \uparrow \\
800 \% \uparrow \\
500-775 \% \uparrow \\
280-400 \% \uparrow\end{array}$ & $\begin{array}{l}11.90 \% \downarrow \\
10 \% \downarrow \\
7.89 \% \downarrow \\
10.81 \% \downarrow \\
8.82 \% \downarrow\end{array}$ \\
\hline
\end{tabular}

Section 4.1.1 with the pilot fuel unable to ignite and sustain acceptable combustion in an overall lean mixture in the cylinder.

\subsubsection{Specific $\mathrm{CO}_{2}$}

Fig. 18(a) presents an experimentally obtained map showing lines of constant specific $\mathrm{CO}_{2}$ for RME based single fueling whereas Fig. 18(b) presents a similar map for RME piloted dual fueling of natural gas. As with the diesel piloted dual fueling natural gas (Fig. 18(b)), RME piloted dual fueling results in lower specific $\mathrm{CO}_{2}$ emissions (Fig. 18(b)) compared to the RME based single fueling (Fig. 18(b)). The difference can attributed be to the reduction in carbon going into the engine in case of dual fueling with natural gas. The data used to plot these maps has been used to tabulate the performance comparison of the two pilot fuels in Table 2 .

\section{Conclusion}

Performance and emissions data have been collected at 6 engine operating speeds and 8 different load settings for single fueling, and 6 load settings for dual fueling. The load settings have been used to determine the brake power the engine is producing. Iso-contours of thermal efficiency, specific $\mathrm{NO}_{X}$, specific $\mathrm{HC}$ and specific $\mathrm{CO}_{2}$ have been traced on a power-speed plots using the data collected. The maps therefore represent operation of the engine over its full speed and power range. It is shown that data collected and presented in this manner highlights aspects of engine operation which may be missed by more conventional engine testing techniques at limited speed and power ranges. The performance of two pilot fuels, diesel and RME, have been examined using these full engine maps. Contrary to most of the most studies presenting performance and emissions characteristics of compression-ignition $(\mathrm{CI})$ engines operating with various fuels, including natural gas, this work has presented experimentally investigated, assessed, compared, and discussed the performance and emissions contours of a natural gas fueled $\mathrm{CI}$ engine with two pilot fuels (diesel and RME).

- Apart from the highest power outputs, the natural gas dual fueling case was less efficient as compared to the respective pilot fuel based single fueling. Whilst the local equivalence ratio in the region of the pilot injection may be near unity (stoichiometric), especially during the initial pre-mixed combustion phase, there can exist some areas with in the combustion chamber away from the pilot region where there is a lean homogeneous mixture of natural gas and air. This argument is supported by relatively lower Fuel to air ratio obtained in case of dual fueling. As the power output increases the dual fuel mode recovers the thermal efficiency losses suffered at the lower power outputs with the dual fuel mode exhibiting slightly higher $F / A$ ratios at these conditions.
- In dual fuel mode the maximum thermal efficiency reached with RME is marginally lower than the maximum thermal efficiency reached with diesel.

- The slope of the constant volumetric efficiency is flatter for natural gas dual fueling with diesel than for baseline diesel operation and the values are lower. This is a consequence of the method used to introduce natural gas into the engine. As the natural gas has been introduced via manifold injection, a portion of the intake air is displaced by the natural gas, reducing the measured volume flow rate of air into the engine. This leads to a reduction of the engine's volumetric flow rate. The slope of the constant volumetric efficiency lines differs due to a change in the scaling of volumetric efficiency with engine speed. As the amount of natural gas added is increased to meet the increase in speed demand, larger amounts of air are displaced. As the natural gas is introduced at the manifold and does not flow through the entire intake system but the air does, the scaling law as noted by Heywood [22] does not hold well.

- Natural gas based dual fueling has resulted in significant reduction in $\mathrm{NO}_{X}$ when compared to the diesel and RME based single fueling cases. This reduction in $\mathrm{NO}_{X}$ is a direct consequence of difference in the in-cylinder mixture composition prior to ignition and combustion events. Significantly higher specific heat capacity of natural gas raises the overall specific heat capacity of the mixture and results in lower temperatures during compression stroke. Also the presence of natural gas affect the peak in-cylinder (adiabatic) temperature. With the formation of $\mathrm{NO}_{X}$ highly dependent on thermal mechanism, the lower in-cylinder temperature results in lower specific $\mathrm{NO}_{X}$ as compared to the single fueling.

- Specific $\mathrm{NO}_{X}$ emissions in case of both single fueling cases are centered in the middle of the map and they decrease in all direction from this region of maximum specific $\mathrm{NO}_{X}$. On the other hand, an opposite trend is observed with natural gas dual fueling where minimum specific $\mathrm{NO}_{X}$ are centered at the middle of the map and they increase in all directions from this region of minimum $\mathrm{NO}_{X}$.

- At lower power outputs across all speeds, the specific HC emissions were significantly higher in case of dual fueling when compared to the respective pilot fuel based single fueling. This can be attributed to low in-cylinder temperature due to relatively higher specific heat capacity of the mixture. As the power was increased at constant speed, the specific HC emissions were significantly reduced, though still higher than the respective single fueling cases. Also, the equivalence ratio threshold for dual fuel modes is 0.4. Below this threshold value, the HC emissions increase whereas increasing equivalence ratio beyond this value results in a decrease in $\mathrm{HC}$ emissions. The equivalence ratio in this case ranges between 0.44 and 0.79 and this is reflected in gradual decrease of $\mathrm{HC}$ emissions as the load increase.

- Studying the specific $\mathrm{NO}_{X}$ and specific $\mathrm{HC}$ maps together has revealed that the region of lower powers at lower speeds in the maps is a place where the engine shows the worst tradeoff between the $\mathrm{NO}_{X}$ and $\mathrm{HC}$ emissions as both of these emissions are higher in this region.

\section{References}

[1] Energy Information Administration US Department of Energy. Washington, DC; 2002.

[2] Akansu S Orhan, Dulger Zafer, Kahraman Nafiz, Vezirolu T Nejat. Internal combustion engines fueled by natural gas and hydrogen mixtures. Int J Hydrogen Energy 2004;29(14):1527-39.

[3] Karavalakis Georgios, Durbin Thomas D, Villela Mark, Miller J Wayne. Air pollutant emissions of light-duty vehicles operating on various natural gas compositions. J Nat Gas Sci Eng 2012;4(0):8-16. 
[4] Richards GA, McMillian MM, Gemmen RS, Rogers WA, Cully SR. Issues for lowemission, fuel-flexible power systems. Prog Energy Combust Sci 2001;27(2):141-69.

[5] Chandra R, Vijay VK, Subbarao PMV, Khura TK. Performance evaluation of a constant speed ic engine on CNG, methane enriched biogas and biogas. Appl Energy 2011;88(11):3969-77.

[6] Korakianitis T, Namasivayam AM, Crookes RJ. Natural-gas fuelled sparkignition (SI) and compression-ignition ( $\mathrm{CI}$ ) engine performance and emissions. Prog Energy Combust Sci 2011;37(1):89-112.

[7] Papagiannakis RG, Hountalas DT. Combustion and exhaust emission characteristics of a dual fuel compression ignition engine operated with pilot diesel fuel and natural gas. Energy Convers Manage 2004:45(1819):2971-87.

[8] Papagiannakis RG, Kotsiopoulos PN, Zannis TC, Yfantis EA, Hountalas DT, Rakopoulos CD. Theoretical study of the effects of engine parameters on performance and emissions of a pilot ignited natural gas diesel engine. Energy 2010;35(2):1129-38. 21st International Conference, on Efficiency, Cost, Optimization, Simulation and Environmental Impact of Energy Systems.

[9] White T, Milton B. Shock wave calibration of under-expanded natural gas fuel jets. Shock Waves 2008:18:353-64.

[10] Namasivayam AM, Korakianitis T, Crookes RJ, Bob-Manuel KDH, Olsen J. Biodiesel, emulsified biodiesel and dimethyl ether as pilot fuels for natural gas fuelled engines. Appl Energy 2010;87(3):769-78.

[11] Korakianitis T, Namasivayam AM, Crookes RJ. Diesel and rapeseed methyl ester (RME) pilot fuels for hydrogen and natural gas dual-fuel combustion in compression-ignition engines. Fuel 2011;90(7):2384-95.

[12] Papagiannakis RG, Rakopoulos CD, Hountalas DT, Rakopoulos DC. Emission characteristics of high speed, dual fuel, compression ignition engine operating in a wide range of natural gas/diesel fuel proportions. Fuel 2010;89(7):1397-406. 17th International Symposium on Alcohol Fuels.

[13] McTaggart-Cowan GP, Rogak SN, Munshi SR, Hill PG, Bushe WK. Combustion in a heavy-duty direct-injection engine using hydrogen-methane blend fuels. Int J Engine Res 2009;10(1):1-13.
[14] Karim GA. A review of combustion processes in the dual fuel engine - the gas diesel-engine. Prog Energy Combust Sci 1980;6(3):277-85.

[15] Karim GA. NIST reference fluid thermodynamic and transport properties database, version 9.1. National Institute of Standards and Technology.

[16] Kusaka Jin, Okamoto Takashi, Daisho Yasuhiro, Kihara Ryouji, Saito Takeshi. Combustion and exhaust gas emission characteristics of a diesel engine dualfueled with natural gas. JSAE Rev 2000;21(4):489-96.

[17] Stewart J, Clarke A, Chen R. An experimental study of the dual-fue performance of a small compression ignition diesel engine operating with three gaseous fuels rid a-2785-2010. Proc Inst Mech Engineers Part D - J Automob Eng 2007;221(D8):943-56.

[18] Hellier Paul, Ladommatos Nicos, Allan Robert, Rogerson John. The influence of fatty acid ester alcohol moiety molecular structure on diesel combustion and emissions. Energy Fuels 2012;26(3):1912-27.

[19] Yoon Seung Hyun, Lee Chang Sik. Experimental investigation on the combustion and exhaust emission characteristics of biogas and biodiesel dual-fuel combustion in a CI engine. Fuel Process Technol 2011;92(5):992-1000.

[20] Ferguson Colin R, Kirkpatrick Allan T. Internal combustion engines. Applied thermal sciences. John Wiley and Sons, Inc.; 2001.

[21] Stone Richard. Introduction to internal combustion engines. 2nd ed. Macmillan Educ.; 1992.

[22] Heywood John B. Internal combustion engines fundamentals. McGraw-Hill series in mechanical engineering. Singapore: McGraw-Hill; 1988.

[23] Papagiannakis RG, Rakopoulos CD, Hountalas DT, Rakopoulos DC. Emission characteristics of high speed, dual fuel, compression ignition engine operating in a wide range of natural gas/diesel fuel proportions. Fuel 2010;89(7):1397-406. 17th International Symposium on Alcohol Fuels.

[24] Korakianitis T, Namasivayam AM, Crookes RJ. Hydrogen dual-fuelling of compression ignition engines with emulsified biodiesel as pilot fuel. Int J Hydrogen Energy 2010;35(24):13329-44. 